\title{
The Community of Inquiry in Writing Studies Survey: Interpreting Social Presence in Disciplinary Contexts
}

\author{
Mary K. Stewart \\ California State University San Marcos \\ Lyra Hilliard \\ University of Maryland \\ Natalie Stillman-Webb \\ University of Utah \\ Jennifer M. Cunningham \\ Kent State University
}

\begin{abstract}
This article applies the Community of Inquiry (CoI) framework to a particular disciplinary context: first-year writing (FYW). Students enrolled in online FYW courses across three institutions ( $\mathrm{n}=$ 272) completed a version of the CoI survey that was slightly modified to fit the disciplinary context of writing studies. A factor analysis was conducted to determine how well the CoI in Writing Studies data aligned with typical CoI survey research; teaching presence and cognitive presence loaded onto single factors, but the social presence items divided into multiple factors. The authors put their findings in conversation with other scholarship about social presence, especially Carlon et al. (2012) and Kreijns et al. (2014), and advocate for differentiating between survey items that relate to "social presence," "social comfort," "attitude," and "social learning." They also recommend that future disciplinary uses of the CoI Survey include survey items that ask students to report on the extent to which they engaged in the types of social learning that the discipline values.
\end{abstract}

Keywords: community of inquiry, first-year writing, blended, online, CoI survey

Stewart, M.K., Hilliard, L., Stillman-Webb, N., \& Cunningham, J.M. (2021). The community of inquiry in writing studies survey: Interpreting social presence in disciplinary contexts. Online Learning, 25(2), 73-94. https://doi.org/10.24059/olj.v25i2.2275 


\section{The Community of Inquiry in Writing Studies Survey: Interpreting Social Presence in Disciplinary Contexts}

In 2000, Garrison, Anderson, and Archer introduced the Community of Inquiry (CoI) framework to investigate whether online students were developing a sense of community and engaging in collaborative learning. Through the coding of discussion forum transcripts, they found that community-based learning was possible in asynchronous, textual, online spaces, especially when three interdependent elements were present: teaching presence, social presence, and cognitive presence. Throughout the next two decades, online learning researchers employed the framework to study the design and assessment of online courses, establishing the usefulness of the framework in a variety of educational contexts (see Internet and Higher Education 2010 special issue). Scholars have also conducted extensive survey research to better understand the relationship between the presences (Shea \& Bidjerano, 2009).

Garrison (2017) reviews the breadth of that CoI research and expounds upon the three elements that his team originally defined. "Teaching presence" is something the teacher establishes through the course design and organization, as well as through the facilitation of student-student and student-content interaction (p. 72-76). A high level of teaching presence establishes clear expectations in an easy-to-navigate learning environment that provides sufficient support for active learning. Students with a high level of "social presence" bring their interests and experiences into that learning environment and view themselves as working toward a common goal alongside their classmates. In this way, social presence creates "a climate that supports and encourages probing questions, skepticism, and the contribution of explanatory ideas" (p. 37). The ultimate goal of a community of inquiry is for students to engage in critical thinking and knowledge construction, or "cognitive presence," which CoI researchers measure according to Dewey's (1993) four phases of practical inquiry: triggering event, exploration, integration, and resolution. All three presences are required to build a CoI: teaching presence creates the environment in which social presence can support learning, i.e., cognitive presence.

While studies applying CoI to online learning have "consistently demonstrated the stability of the CoI framework" (Garrison, 2017, p. 28), researchers have called for context-specific investigations. As Garrison \& Arbaugh (2007) explain, the CoI framework was developed based on data from courses in the field of education, and applications of $\mathrm{CoI}$ to other disciplines are necessary before it can be generalized. They also note that cross-disciplinary investigations can facilitate conversations about the "non-inquiry aspects of the online learning experience" (p. 167), thus pushing scholars to articulate whether the theory that grounds the framework aligns with the theories that guide disciplinary pedagogies.

Our project joins others (e.g., Wicks et al, 2015) that respond to the call for context-specific applications of the framework. We examine a particular disciplinary context (online first-year writing) and a particular student population (those enrolled in a required, first-year, general education course). We employed a modified version of the CoI survey (Arbaugh et al., 2008), which we are calling the "CoI in Writing Studies" survey, as an instrument for measuring the extent to which writing students perceive their online courses as communities of inquiry. We surveyed students enrolled in online FYW courses across three institutions $(n=272)$ and found that our modifications impacted the way students reported on their perceptions of social presence. More specifically, while a factor analysis supported one-factor solutions for teaching and cognitive presence, our data was best represented by a multi-factor solution for social presence. This article shares the results, building upon Carlon et al. (2012) and Kreijns et al. (2014) to differentiate 
between survey items that relate to "social presence, "social comfort," "attitude," and "social learning." We also reflect on the uses and interpretations of the CoI survey in particular disciplinary contexts and make recommendations for other discipline-specific applications of CoI.

\section{Review of Relevant Literature}

Over the last ten years, the CoI survey (Arbaugh et al., 2008) has proved a reliable measurement of the three constructs in the CoI framework, which researchers consistently report are positively correlated (Kozan \& Richardson, 2014). Much of the existing CoI Survey research focuses on the relationship between the three presences (Lambert \& Fisher, 2013), or on the relationship between the survey responses and other variables such as course grades (RockinsonSzapkiw et al., 2016), student satisfaction and perceived learning (Akyol \& Garrison, 2008), and retention (Boston et al., 2009). While some researchers have proposed modifications to the framework (e.g., Shea et al.'s (2012) "learning presence" and Cleveland-Innes and Campbell's (2012) "emotional presence"), the original three-presence framework is more commonly used in empirical studies (Caskurlu, 2018; Stenbom, 2018). Our project contributes to ongoing conversations about the role of social presence within the CoI framework, especially in terms of how social presence is measured by the CoI survey.

In his review of CoI research, Garrison (2007) notes that early scholarship primarily focused on social presence, and most of that work examined social presence in isolation. However, Garrison argues that social presence must be considered alongside the other presences, especially cognitive presence. A true CoI, Garrison maintains, requires more than "feeling real" or experiencing a social relationship; a community of inquiry requires "common purposes and inquiry," which means that the online course must be deliberately designed to include "collaborative assignments where students can benefit from the perspectives of others" (Garrison, 2007, p. 63). From a CoI perspective, those collaborative assignments should leverage teaching presence during design and facilitation, and they should guide students through the four phases of practical inquiry that characterize cognitive presence.

For Garrison, inquiry as a result of interaction is the primary purpose of social presence. However, Garrison also recognizes that social relationships need to be developed before that inquiry is possible. Drawing on the three theoretically derived categories of social presence (affective communication, open communication, and group cohesion), Garrison speculates that community of inquiry participants may "progress from socio-emotional connections, to establishing a climate of open communication, and then naturally engage in purposeful activities (and cohesive comments)" (p. 64). Caskurlu (2018) also examines the relationship between the three categories of social presence, conducting a confirmatory factor analysis of the social presence survey items to determine if there is an empirical basis for the categories. Caskurlu ultimately maintains the three-factor model for social presence, but the results indicated that a two-factor solution was also worth considering: affective/interpersonal communication and group cohesion were less distinct from each other, while open communication was decidedly distinct from the other two. Thus, unlike Garrison's speculation that affective communication and open communication build towards group cohesion, Caskurlu's study suggests that affective communication and group cohesion may function similarly, while open communication is distinct. Potentially, affective communication and group cohesion may be creating the interpersonal relationships that enable collaborative inquiry via open communication. 
Several other scholars offer additional refinements to the ways in which social presence is understood. Armellini \& De Stefani (2016) identify three types of social presence: interactions for learning, which is a combination of social and teaching presence that scaffolds "the learning process and creates opportunities to promote higher-order thinking" (p. 1213); socialization of content, which is a combination of social and cognitive presence that involves the negotiation and exploration of multiple perspectives; and community development, which is "social presence per se" (p. 1213). In a similar vein, Peacock \& Cowan (2019) examine overlaps between the presences, which they term "influences." They differentiate between a "trusting influence," which they situate at the intersection of social and teaching presence, and "meaning-making," which they situate at the intersection of social and cognitive presence. This approach foregrounds the widely accepted belief that teaching presence creates the conditions in which comfort and trust can grow; we might think of this as the social-relationship variety of social presence that helps participants "feel real." The trust established through teaching-social presence then creates an environment where "meaning-making" is possible, which we might think of as the collaborative-inquiry variety of social presence that helps students learn as a result of interacting with peers.

Carlon et al. (2012) more explicitly distinguish between two forms of social presence in their study that sought to validate the CoI survey for a specific disciplinary context (nursing education) and student population (nontraditional adults). They replicated Shea \& Bidjerano's (2009) factor analysis and found that the teaching presence and cognitive presence findings were consistent, but the social presence items formed two factors instead of one. The five social presence items that begin with "I felt..." (items \#17-21 on the original survey) formed one factor, and the three remaining social presence items (\#14-16 on the original survey) formed a second. Carlon et al. name these factors "social comfort" and "social experience." Social comfort is similar to Peacock \& Cowan's trusting influence or Armellini \& De Stefani’s interactions for learning, while social experience is closer to meaning making or socialization of content.

Kreijns et al. (2014) build upon Carlon et al.'s study, offering a theoretical discussion of social presence. They point out that the early definition of social presence (Short et al., 1976) contains two separate constructs: “(1) 'social presence' (i.e., the degree of 'realness' of the other in the communication), and (2) 'social space' (i.e., the degree to which social interpersonal relationships are salient)" (p. 7). They argue that both constructs are present in the CoI definition of social presence, but CoI scholarship tends to treat them as "equal ... rather than viewing the latter as a consequence" (p. 6). Kreijns et al. apply this theory to an examination of the CoI Survey. They associate only one survey item with "social presence" (item \#15 on the original survey, which states that participants "form distinct impressions" of one another), and they associate four items with "social space" (\#14, 20-22 on the original survey). They sort the remaining items into two categories, which they argue are not truly related to the original definition of social presence: they label item \#16 ("online or web-based communication is an excellent medium for social interaction") as "attitude," and they draw on Carlon et al. to group items \#17-19 into a "social comfort" category.

These attempts to articulate the nuances of social presence contribute to questions about what types of social presence are required to support learning, if at all. Annand's (2011) review of scholarship on social presence suggests that there is actually very little empirical support for the argument that social presence directly supports perceived or actual learning. Instead, the research shows that "appropriately structured learning materials, timely, noncontiguous, one-on-one instructor-learner communication, and a teaching focus that enhances individual learner attributes 
and effort may be the best prescriptions for effective online learning in higher education" (p. 49). In these prescriptions, there is a clear relationship between the student and the instructor, but not between the student and peers, which gives some support for the separation of social presence into at least two categories, one more related to social-teaching presence and feelings of comfort (i.e., Peacock \& Cowan's trusting influence; Armellini \& De Stefani's interactions for learning; Carlon et al.'s and Kreijns et al.'s social comfort), and the other more related to social-cognitive presence and collaborative learning (i.e., Peacock \& Cowan's meaning-making; Armellini \& De Stefani's socialization of content; Garrison's inquiry as a result of interaction). By treating these varieties of social presence as distinct, we may be able to draw more concrete conclusions about what types of social presence (if any) best support student satisfaction and/or student learning in particular courses.

It is also important to recognize that a community of inquiry is a particular type of learning environment that may not be appropriate for all learning situations. Lowenthal \& Snelson (2017) make this argument:

The CoI framework is an idealized model for a certain type of online course (i.e., collaborative online environments), and possibly a certain type of learner (Annand, 2011; Arbaugh, Bangert, \& Cleveland-Innes, 2010). This suggests that the CoI framework might be of limited value for online courses that rely little, if at all, on collaborative assignments or for students who do not value heavy social interaction. (p. 151)

Often, those "collaborative assignments" that characterize a CoI course involve some form of group work (e.g., Peacock \& Cowen, 2019) or the frequent sharing and exploring of multiple perspectives about course content in a discussion forum (e.g., Akyol \& Garrison, 2008). In a writing studies context, students engage in collaboration through activities like peer review (Corbett, LaFrance, \& Decker, 2014). However, while some FYW courses involve collaborative writing (Kennedy \& Howard, 2014), most writing students ultimately produce individual work (i.e., individually authored essays or multimodal compositions), which can give students the impression that collaborative activities are intended to support surface-level interaction and not knowledge co-construction. Nevertheless, composition theory highly values collaborative learning and explicitly aims to teach writing as a social process (Gere, 1987; Bruffee, 1999; Wardle \& Adler-Kassner, 2015). Writing instructors want students to understand writing and reading as socially situated actions and to practice a writing process that requires collaboration via feedback and revision.

Consequently, while we recognize that a community of inquiry is just one possible way to organize an online course (Lowenthal \& Snelson, 2017), it is appropriate for a first-year writing context (Gillam \& Wooden, 2013). Because of the challenge of teaching students that a seemingly individual activity is inherently collaborative, our discipline requires a nuanced understanding of what varieties of social presence exist in online writing courses, and what combination of those varieties lead to genuinely collaborative learning. As a first step in that direction, this study analyzes online writing students' responses to the CoI in Writing Studies survey, questioning (a) how their understanding of social presence relates to previous CoI research, and (b) if the survey responses provide any evidence of community-based inquiry and knowledge co-construction. 
Research Questions:

(a) How do FYW students' responses to the CoI in Writing Studies survey align with past CoI survey research, especially as it relates to social presence?

(b) To what extent does the CoI in Writing Studies survey data provide evidence of community-based inquiry and/or knowledge co-construction in FYW?

\section{Methods}

This article reports on quantitative survey data collected as part of a larger, IRB-approved project that involved surveying and interviewing blended and online first-year writing (FYW) students and instructors throughout 2017-2018.

\section{Participants and Research Sites}

This research includes undergraduate students enrolled in online FYW classes at three fouryear universities in the United States. The institutions include a mid-Atlantic public university, a regional campus of a midwestern university, and a public research university in the Intermountain West region. The institutions range in size, from 5,000 to 32,000 students, and vary in their diversity, from $14 \%$ to $28 \%$ of students identifying as minorities.

We delivered the survey to 1,139 students and received 272 responses (24\%). Of those 272 students, $76 \%$ identified as female, $22 \%$ identified as male, $1 \%$ identified as gender nonconforming, and $1 \%$ preferred not to say. The majority of respondents were ages $18-22(87 \%)$ and spoke English as their first language (95\%). Approximately one half (47\%) were sophomores, $12 \%$ were freshmen, $27 \%$ were juniors, $10 \%$ were seniors, and $4 \%$ responded "other." The number of sophomores in the study is likely due to the fact that Institution A offers a two-course sequence and students often take the second course in their second year; it may also be that first-year students at these institutions are less likely to take their writing courses in the online format.

Approximately $61 \%$ of respondents $(n=167)$ were enrolled at Institution A, 19\% $(n=51)$ at Institution B, and 20\% $(\mathrm{n}=54)$ at Institution $\mathrm{C}$. The courses at each institution were fully online and asynchronous, and the majority of respondents had prior experience with online learning: $52 \%$ had taken 3 or more online courses in the past, $39 \%$ had taken 1-2 previous online courses, and only $9 \%$ had never taken an online course.

\section{Disciplinary Context}

The survey respondents were all enrolled in first-year writing. These courses are small, ranging from 19 to 28 students, and are typically taught by instructors who are committed to active, student-centered learning. Students produce a variety of writing assignments throughout the semester and engage in individual and small group activities, such as peer review, to prepare them for drafting and revising.

Institution A's curriculum focuses on research writing, Institution B's focuses more broadly on the writing process, as well as argument and research writing, and Institution C's emphasizes reading and writing practices for participating in academic conversations, as well as developing information literacy and constructing academic arguments. All of the courses require students to produce individually authored essays. 
The writing programs at Institutions A and B provide their instructors with course handbooks or instructor manuals and support websites that recommend readings and assignments, but instructors have agency over course design. Institution $\mathrm{C}$ provides new instructors with a standard syllabus and set of assignments that instructors adapt as they continue teaching. Institution B also requires online pedagogy training: all online instructors participate in a workshop delivered by an instructional designer and faculty member. Institution $\mathrm{C}$ offers an online pedagogy course that is required for online graduate student instructors and optional for faculty. There is no formal training for online instructors at Institution A.

While some instructors at these institutions are aware of CoI research, to our knowledge, none of the courses were designed according to the CoI framework. Nevertheless, because of the nature of writing instruction, we are confident that all of the courses in this study expected students to interact with peers and co-construct knowledge during peer review and possibly during discussion forums or group projects.

\section{Instrument}

This research is informed by two previous projects that modified the CoI survey (Arbaugh et al., 2008) to make it specific to writing instruction (Stewart, 2019; Hilliard \& Stewart, 2019). The revised instrument is comprised of 35 multiple choice questions and four open-ended questions (see Appendix B).

The survey questions were initially revised by Stewart in consultation with the other authors of this article. The goal was to move away from asking about "course content" because writing courses are more focused on skills development than on content mastery. Consequently, the revisions ask about "writing skills" or "course activities" instead of "course content." For example, instead of "problems posed increased my interest in course issues," the modified survey states "course assignments increased my interest in writing." In December 2016, Stewart conducted a 45-minute, semi-structured interview with a student who read through each item on the survey and explained what she thought the question meant and how she would respond. Stewart and Hilliard revised and finalized the modified CoI in Writing Studies survey.

In total, eight cognitive presence, one social presence, and two teaching presence items were rephrased. We also added one item to the social presence category and organized the survey such that students responded to social presence items first, then cognitive presence items, and then teaching presence items. See Appendix A for a comparison of the original and modified items.

In 2017, Stewart delivered the modified survey to four sections $(n=100)$ of an online research writing course at Institution A. Thirty-two students responded to the survey. Analysis of internal consistency confirmed that the modified survey items reliably measured the three constructs of the CoI framework: the Cronbach alpha coefficient for each presence was cognitive presence $=0.91$, social presence $=0.84$, teaching presence $=0.94$. The added survey item, "interacting with classmates improved my writing," positively impacted the internal consistency of social presence; without that item, the coefficient was 0.81 . Stewart also conducted a regression analysis to examine the relationship between the presences. The highest percentage of variance was explained when the model included cognitive presence as the dependent variable, and the total variance explained by that model was $54 \%, \mathrm{~F}(2,28)=16.62, \mathrm{p}=.000$, with both teaching presence (beta $=.34, \mathrm{p}=.024)$ and social presence (beta $=.51, \mathrm{p}=.001$ ) as significant predictors. This analysis thus demonstrated an alignment between the modified survey data and the theoretical constructs in the CoI framework, prompting Stewart and Hilliard to move forward with the 
modified CoI in Writing Studies survey as a measurement of the extent to which writing students experience the three CoI presences in their hybrid writing courses (e.g., Hilliard \& Stewart, 2019).

The larger sample size of this present study $(n=272)$ allowed us to conduct a factor analysis to further explore the ways in which the CoI in Writing Studies survey might vary from the original CoI survey. See Results for more details.

\section{Data Collection \& Analysis}

In 2017-2018, 272 online writing students completed the CoI in Writing Studies survey. The authors used Qualtrics to create online versions of the survey at their institutions. Initial email invitations and three follow-ups were sent to online writing students over a three-week period in the last month of the semester; embedded data was used to track course sections. Prior to delivering these emails, we contacted course instructors, providing an opportunity to opt out of the study. To incentivize participation, the first ten respondents at each institution received a $\$ 5$ Amazon gift card, and all respondents who completed the survey at a given institution had the opportunity to enter into a drawing for a $\$ 50$ Amazon gift card.

Prior to sharing our institutional data with the research team, each researcher removed identifying information (e.g., email addresses). In the event that our own courses were included in the study, another research team member delivered the survey.

The quantitative data was analyzed descriptively and inferentially in SPSS.

\section{Limitations}

The response rate to the survey was relatively small $(24 \%)$, and the participants are not equally distributed across institutions (61\% enrolled at institution A). It is also the case that Institution A's course was specifically focused on research writing, while the other two institutions were more traditional first-year writing courses. Consequently, the generalizability of the data is limited. On the other hand, the sample size was substantive enough $(n=272)$ to warrant a factor analysis, which provided useful information that has implications for future uses of the CoI in Writing Studies survey.

The project would have been strengthened if the authors had collected additional demographic information from the students (especially racial identity) and pedagogical information from the instructors (especially what activities, if any, were intended to prompt inquiry as a result of interaction).

\section{Results}

The first research question examined the extent to which FYW students' responses to the $\mathrm{CoI}$ in Writing Studies survey align with CoI survey research more generally. We conducted a factor analysis to answer this question, finding a single-factor solution for teaching and cognitive presence and a multi-factor solution for social presence. The second research question explored the extent to which the CoI in Writing Studies survey data provided evidence of community inquiry and knowledge co-construction in FYW. We found that students felt comfortable in the course, but we did not find extensive evidence of the types of community inquiry and knowledge coconstruction that writing studies values. 


\section{RQ1-CoI in Writing Studies}

After inspecting the correlation matrix and confirming the presence of many coefficients of 3 and above, the 35 items of the CoI in Writing Studies survey were subjected to factor analysis using SPSS version 26. The Kaiser-Meyer-Oklin value was .96 (Kaiser, 1970, 1974) and Bartlett's Test of Sphericity (Bartlett, 1954) reached statistical significance $(\mathrm{p}=.000)$. Replicating the methods of Shea \& Bidjerano (2009) and Carlon et al. (2012), we conducted principle axis factoring with a direct oblimin rotation. We considered factor loadings of .3 or higher to be "significant."

The analysis revealed four factors with eigenvalues exceeding 1, explaining $56.7 \%, 6.0 \%$, $3.8 \%$, and $2.3 \%$ of the variance, respectively. While Catell's (1966) scree test might suggest that we retain only two of the factors, our theoretical knowledge of CoI led us to retain all four. The four-factor solution explained $69 \%$ of the variance. The oblimin rotation indicated that all teaching presence items loaded onto a single factor (with pattern coefficients ranging from .749-.957) and all cognitive presence items loaded onto a single factor (with pattern coefficients ranging from .457-.861). The social presence items, however, divided into two factors, which we describe in more detail below. Examination of the factor correlation matrix indicated that the fourth factor was weakly correlated with the other three (.272-.336), but factors $1-3$ were moderately correlated (.512-.770). Consequently, unlike Carlon et al., we did not repeat the analysis with a varimax rotation.

We also forced a three-factor solution to compare our data with the three-presence CoI model and found that the model explained $66 \%$ of the variance, which is only $3 \%$ less than the four-factor model. However, it was not the case that the three-factor solution aligned with the original CoI presences; instead, the five items that formed Factor 3 in the four-factor model formed one factor, and the remaining social presence items loaded with the cognitive presence factor. As such, we determined that the four-factor model was a better fit for this data.

In the four-factor model, most of the social presence items loaded onto two distinct factors. Five social presence items loaded onto a single factor (with coefficients ranging from .618-.820), and three social presence items loaded onto a separate factor (with coefficients ranging from .324.540 ). It was also the case that two of the items that loaded onto the second factor (social learning) cross-loaded with cognitive presence, but their social learning coefficients were higher.

\section{Table 1}

Two-Factor Model for Social Presence

\begin{tabular}{|c|c|c|c|}
\hline \multicolumn{2}{|l|}{ Social Comfort } & \multicolumn{2}{|l|}{ Social Learning } \\
\hline Item & Coefficient & Item & Coefficient \\
\hline $\begin{array}{l}\text { I felt comfortable interacting with other } \\
\text { course participants. }\end{array}$ & .820 & $\begin{array}{l}\text { Interacting with classmates improved my } \\
\text { writing.** }\end{array}$ & .540 \\
\hline $\begin{array}{l}\text { I felt comfortable participating in the } \\
\text { course discussions. }\end{array}$ & .780 & $\begin{array}{l}\text { Online discussions helped me to develop } \\
\text { as a writer.* }\end{array}$ & .514 \\
\hline
\end{tabular}




\begin{tabular}{ll|l}
\hline $\begin{array}{l}\text { I felt comfortable conversing through the } \\
\text { online medium. }\end{array}$ & $\begin{array}{l}\text { Getting to know other course } \\
\text { participants gave me a sense of } \\
\text { belonging in the course }\end{array}$ \\
$\begin{array}{l}\text { I felt comfortable disagreeing with other } \\
\text { course participants while still } \\
\text { maintaining a sense of trust. }\end{array}$ & \\
$\begin{array}{l}\text { I felt that my point of view was } \\
\text { acknowledged by other course } \\
\text { participants. }\end{array}$ & .618
\end{tabular}

*Modified item from original CoI Survey.

**Item did not exist on original CoI Survey.

As illustrated in Table 1, the first social presence factor included items that were unchanged from the original CoI survey, and those items primarily describe the participants feeling comfortable in the online environment. These same five survey items form Carlon et al.'s (2012) social comfort factor. ${ }^{1}$ The second social presence factor in our study included an item that we modified and the item that we added, as well as a social presence item traditionally affiliated with interpersonal communication; because these three items are related to students learning from peers, we named the factor "social learning."

It was also the case that one of the social presence items did not load with any of the factors, and one loaded with the cognitive presence factor, but with a small coefficient (.302). Interestingly, these were the same two items that Kreijns et al. (2014) separated from the other social presence items, naming the first "social presence" and the second "attitude."

Social Presence = "I was able to form distinct impressions of some course participants." (loaded with cognitive presence, but with a small coefficient)

Attitude = "Online or web-based communication is an excellent medium for social interaction." (did not load with any factors)

Consequently, we have maintained Kreijns et al.'s two single-item constructs in our understanding of the varieties of social presence represented on the CoI in Writing Studies survey.

Like Carlon et al. (2012) and Kreijns et al. (2014), this factor analysis differentiates between several aspects of social presence. Our 'social comfort" factor matches Carlon et al.'s social comfort factor, and our findings provide empirical support for Kreijns et al.'s theoretical identification of "social presence" and "attitude" as individual constructs. Our modifications of the survey have also identified a fourth element, which we are calling "social learning," in place of what Carlon et al. called "social experience" and what Kreijns et al. called "social space" (see Table 2).

\footnotetext{
${ }^{1}$ When we ran a factor analysis that only included the social presence items, we found the same two-factor solution that Carlon et al. (2012) found. The results we report here are from a factor analysis that included all items on the CoI in Writing Studies survey.
} 
Table 2

Social Presence in Carlon et al. Versus Kreijns et al. Versus This Article

\begin{tabular}{|c|c|c|c|c|c|c|c|c|c|c|}
\hline & \multicolumn{2}{|c|}{ Carlon et al. (2012) } & \multicolumn{4}{|c|}{ Kreijns et al. (2014) } & \multicolumn{4}{|c|}{ This Article } \\
\hline & $\begin{array}{c}\text { Social } \\
\text { Comfort }\end{array}$ & $\begin{array}{c}\text { Social } \\
\text { Experience }\end{array}$ & $\begin{array}{c}\text { Social } \\
\text { Comfort }\end{array}$ & $\begin{array}{c}\text { Social } \\
\text { Presence }\end{array}$ & Attitude & $\begin{array}{l}\text { Social } \\
\text { Space }\end{array}$ & $\begin{array}{c}\text { Social } \\
\text { Comfort }\end{array}$ & $\begin{array}{c}\text { Social } \\
\text { Presence }\end{array}$ & Attitude & $\begin{array}{c}\text { Social } \\
\text { Learning }\end{array}$ \\
\hline $\begin{array}{l}\text { I felt comfortable interacting } \\
\text { with other course } \\
\text { participants. }\end{array}$ & $\mathrm{X}$ & & $\mathrm{X}$ & & & & $\mathrm{X}$ & & & \\
\hline $\begin{array}{l}\text { I felt comfortable } \\
\text { participating in the course } \\
\text { discussions. }\end{array}$ & $\mathrm{X}$ & & $\mathrm{X}$ & & & & $\mathrm{X}$ & & & \\
\hline $\begin{array}{l}\text { I felt comfortable conversing } \\
\text { through the online medium. }\end{array}$ & $\mathrm{X}$ & & $\mathrm{X}$ & & & & $\mathrm{X}$ & & & \\
\hline $\begin{array}{l}\text { I felt comfortable disagreeing } \\
\text { with other course participants } \\
\text { while still maintaining a } \\
\text { sense of trust. }\end{array}$ & $\mathrm{X}$ & & & & & $\mathrm{X}$ & $\mathrm{X}$ & & & \\
\hline $\begin{array}{l}\text { I felt that my point of view } \\
\text { was acknowledged by other } \\
\text { course participants. }\end{array}$ & $\mathrm{X}$ & & & & & $\mathrm{X}$ & $\mathrm{X}$ & & & \\
\hline $\begin{array}{l}\text { I was able to form distinct } \\
\text { impressions of some course } \\
\text { participants. }\end{array}$ & & $\mathrm{X}$ & & $\mathrm{X}$ & & & & $\mathrm{X}$ & & \\
\hline $\begin{array}{l}\text { Online or web-based } \\
\text { communication is an } \\
\text { excellent medium for social } \\
\text { interaction. }\end{array}$ & & $\mathrm{X}$ & & & $\mathrm{X}$ & & & & $\mathrm{X}$ & \\
\hline $\begin{array}{l}\text { Getting to know other course } \\
\text { participants gave me a sense } \\
\text { of belonging in the course. }\end{array}$ & & $\mathrm{X}$ & & & & $\mathrm{X}$ & & & & $\mathrm{X}$ \\
\hline $\begin{array}{l}\text { Online discussions helped me } \\
\text { to develop "a sense of } \\
\text { collaboration" (original) / "as } \\
\text { a writer" (modification). }\end{array}$ & & $\mathrm{X}$ & & & & $\mathrm{X}$ & & & & $\mathrm{X}$ \\
\hline $\begin{array}{l}\text { Interacting with classmates } \\
\text { improved my writing. }\end{array}$ & \multicolumn{2}{|c|}{$\begin{array}{l}\text { Did not exist on } \\
\text { original CoI } \\
\text { survey. }\end{array}$} & \multicolumn{4}{|c|}{ Did not exist on original CoI survey. } & & & & $\mathrm{X}$ \\
\hline
\end{tabular}

To test the reliability of the items associated with each factor, we examined the Cronbach's alpha coefficient and found that each group was highly reliable: .955 for cognitive presence, .977 for teaching presence, .883 for social comfort, and .833 for social learning. 


\section{RQ2-Evidence of Community Inquiry}

To explore the extent to which this survey data demonstrates that online writing students are experiencing community inquiry or engaging in knowledge co-construction, we examined students' average responses to the teaching presence and cognitive presence items, as well as to the four aspects of social presence that our factor analysis revealed: social comfort, social learning, social presence, and attitude.

On average, students reported that they "strongly agreed" or "agreed" with the teaching presence items (4.14) and that they "agreed" or felt "neutral" about the cognitive presence items (3.81). These findings are consistent with previous research on communities of inquiry (Shea \& Bidjerano, 2009), as studies consistently report that students more positively perceive teaching presence than cognitive presence (Diaz et al., 2010; Lambert \& Fisher, 2013). That research also typically indicates that the social presence average is lower than the cognitive presence average. Our study somewhat corroborates that work, as students' average responses to the social learning (3.62), social presence (3.54), and attitude (3.53) items were lower than their average responses to teaching and cognitive presence items. However, their responses to the social comfort items were higher (4.21), on average, than their responses to teaching or cognitive presence (see Figure 1).

\section{Figure 1}

Average Scores for TP, CP, and four aspects of SP.

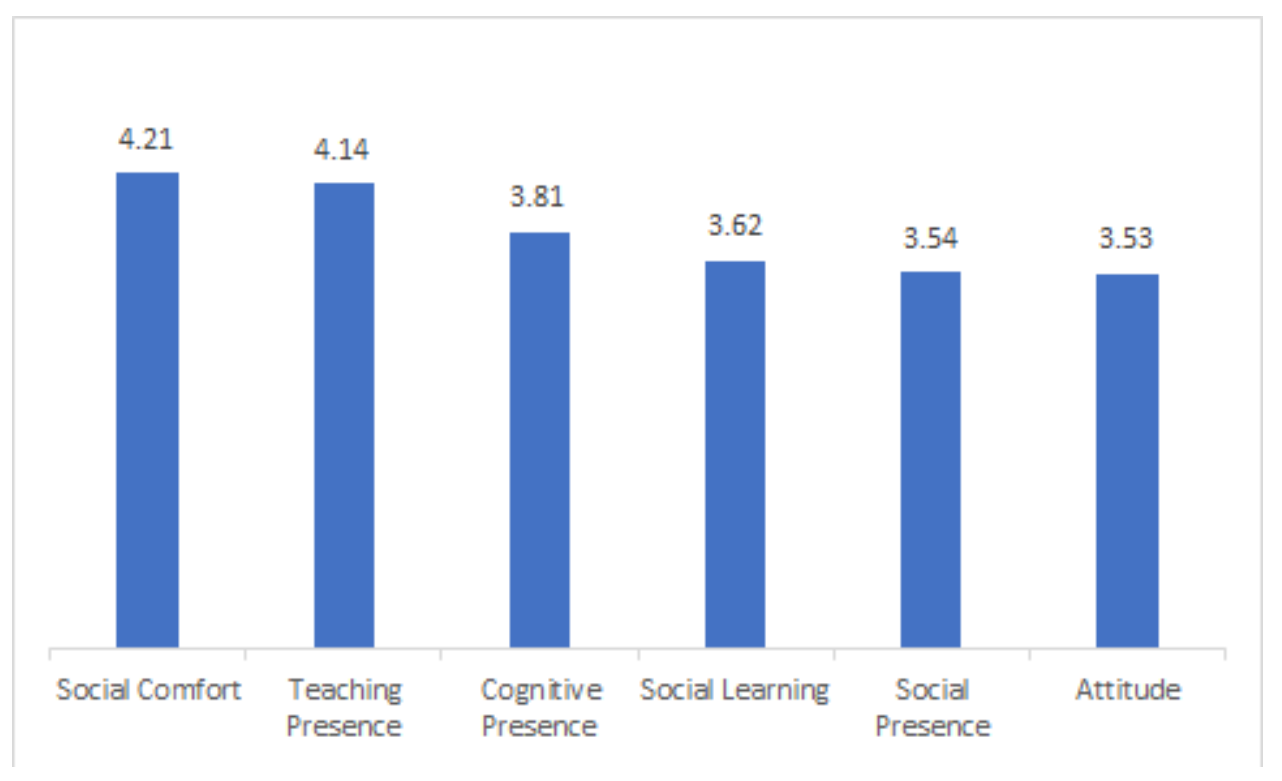

A correlation analysis revealed that all of these elements are positively and significantly correlated with each other, and social learning is more strongly correlated with both teaching and cognitive presence than the other social presence constructs (see Table 3). Social learning is also more strongly correlated with cognitive presence than with teaching presence. 
Table 3

TP, CP, and Four Aspects of SP Correlation Matrix

\begin{tabular}{llllll}
\hline & Social Learning & Social Comfort & Social Presence & Attitude & $\begin{array}{c}\text { Cognitive } \\
\text { Presence }\end{array}$ \\
\hline $\begin{array}{l}\text { Teaching } \\
\text { Presence }\end{array}$ & $.684^{* *}$ & $.586^{* *}$ & $.528^{* *}$ & $.532^{* *}$ & $.796^{* *}$ \\
$\begin{array}{l}\text { Cognitive } \\
\text { Presence }\end{array}$ & $.757^{* *}$ & $.639^{* *}$ & $.593^{* *}$ & $.553^{* *}$ & \\
Attitude & $.603^{* *}$ & $.522^{* *}$ & $.497^{* *}$ & \\
Social Presence & $.570^{* *}$ & $.511^{* *}$ & & \\
Social Comfort & $.639^{* *}$ & & & \\
\hline
\end{tabular}

** $\mathrm{p}<.001$

To further learn about the relationship between these constructs, we ran a series of multiple regression analyses, examining if the four elements of social presence predict students' perceptions of teaching and cognitive presence. We found that, when teaching presence was the dependent variable, the total variance explained was $52 \%, \mathrm{~F}(4,258)=68.90, \mathrm{p}<.000$. Social comfort $(\mathrm{p}=$ $.001)$, social learning $(\mathrm{p}=.000)$, and social presence $(.021)$ were significant predictors, and social learning had a higher beta coefficient (.409 versus .202 and .128, respectively). We found similar results when cognitive presence was the dependent variable: the total variance explained was $63 \%$, $F(4,256)=105.535, p<.000$; social comfort $(p=.000)$, social learning $(p=.000)$, and social presence $(\mathrm{p}=.003)$ were significant predictors, with social learning again having the highest beta coefficient (.494). In both cases, attitude was not a significant predictor of teaching or cognitive presence.

Ultimately, the highest percentage of variance was explained when the model included cognitive presence as the dependent variable and teaching presence, social learning, and social comfort as independent variables. The total variance explained was $72 \%, \mathrm{~F}(3,247)=217.246$, $\mathrm{p}=.000$, and all three independent variables were significant predictors, with teaching presence (.479) having the highest beta coefficient, followed by social learning (.338), and then social comfort (.146).

These findings indicate that students' perceptions of social learning influence their overall perceptions of the course, but the average rating of the social learning items (3.62 out of 5) is not high enough for us to conclude that these students believed they were engaging in substantial community-based inquiry or knowledge co-construction in online FYW.

\section{Discussion}

The original CoI survey aims to measure students' perceptions of the extent to which their courses promote social, teaching, and cognitive presence. Stenbom's (2018) comprehensive literature review of CoI survey research explains that the survey has provided insights into several important conversations about online learning, including online versus blended courses, 
asynchronous versus synchronous modalities, disciplinary differences, and student retention. The CoI survey has helped researchers understand students' experiences with online instruction, and the three presences are clearly useful elements in understanding this instruction.

However, Stenbom's review does not indicate that CoI survey research empirically demonstrates that students are engaging in community-based inquiry and collaborative knowledge co-construction. Put another way, positive responses to the CoI survey do not necessarily mean that the courses under study are functioning as communities of inquiry. This article's factor analysis of the CoI in Writing Studies survey indicates that, in order to understand whether courses are functioning as communities of inquiry, we need a more nuanced understanding of what, exactly, the social presence survey items measure.

As such, this study contributes to the ongoing conversation about social presence among CoI scholars. Annand's (2011) review of social presence literature indicates that we lack empirical evidence of peer interaction facilitating learning. Annand thus questions the assumption at the heart of the CoI framework: "whether social presence and sustained, continuous, two-way communication (an integral component of it) is necessary at all to facilitate the development of higher-order cognitive presences and thence deep and meaningful learning" (43; emphasis in original). To justify such an assumption, Annand argues that we need to "explain more clearly how the learning environments studied and best educational practices prescribed actually differ from those based on learning theories arising from an objectivist orientation" (51; emphasis in original). Our discipline-specific application of CoI responds to that call, because writing pedagogy is deeply committed to collaborative and constructivist theories of learning (Gere, 1987; Gillam \& Wooden, 2013; Bruffee, 1999; Wardle \& Adler-Kassner, 2015). However, to measure if peer interaction facilitated the collaborative learning that writing studies values, we found that we needed to modify the CoI survey so that it more explicitly asked students if they felt that they were learning about writing as a result of interacting with peers.

Our modifications made two distinct elements of social presence empirically visible: social comfort versus social learning. Perhaps unsurprisingly, the students in our study were more likely to report that they feel comfortable than to report that they are learning from peers, forming distinct impressions of peers, or perceiving the online medium as excellent for social interaction. These findings might be interpreted as support for Annand's argument, prompting us to question: is it sufficient for students to feel comfortable online? Do they also need to believe that interacting with peers directly impacts their learning? Is the type of social presence that facilitates knowledge coconstruction necessary for meaningful learning in online writing courses? On the other hand, correlation and regression analysis indicated that both social learning and social comfort influence how students perceive teaching and cognitive presence, with social learning being the more significant predictor. More research is needed to understand the relationship between social comfort and social learning, and to understand if social interactions are necessary for meaningful learning in a writing studies context, but this study joins the clear call in CoI scholarship for distinguishing between the two (Armellini \& De Stefani, 2016; Peacock \& Cowan, 2019).

On a more practical level, our study offers some concrete recommendations for interpreting social presence via the CoI survey. We conducted a factor analysis that identified four discrete social presence constructs across the social presence survey items: social learning, social comfort, social presence, and attitude. While social comfort, social presence, and attitude were each identified and theorized in previous research (Carlon et al., 2012; Kreijns et al., 2014), our 
conception of social learning as a construct on the CoI survey is unique and was made possible because we modified the survey for our disciplinary context.

We added an item, "Interacting with classmates improved my writing," and we revised "Online discussions helped me to develop a sense of collaboration" to read "Online discussions helped me to develop as a writer." In both cases, the items directly ask if students believe they learned as a result of interacting with peers, and they focus on the type of social learning that we expect students in our discipline to experience. In addition to the two items we modified/added, the social learning factor includes a third item, unchanged from the original CoI survey: "Getting to know other course participants gave me a sense of belonging in the course." The presence of this item in the social learning factor suggests that a sense of belonging is an important pre- or corequisite for social learning, at least in a writing studies context.

We recommend that other scholars who apply CoI to their disciplinary contexts follow suit, similarly modifying "online discussions helped..." and adding "interacting with classmates improved..." but replacing "my writing" and "as a writer" with phrases that describe the learning goals their discipline values. For example, if the survey was being delivered to Literature students, the items might read, "Interacting with classmates improved my understanding of the literature we read in this class," and "Online discussions helped me to interpret and analyze literature."

We additionally recommend that future CoI survey researchers distinguish between social comfort and social learning and treat the two single-item constructs (social presence = "I was able to form distinct impressions of some course participants"; attitude = "online or web-based communication is an excellent medium for social interaction") as separate aspects of social presence. Future research might explore whether demographic data (i.e., year, major, firstgeneration college student status) or pedagogical strategies (i.e., discussion forums versus collaborative writing projects) influence how students perceive the four aspects of social presence.

\section{Conclusion}

This study aims to contribute to conversations about social presence and to aid future researchers in disciplinary uses of the CoI survey. Before delivering the CoI survey, researchers should question what type of learning communities they expect their discipline to facilitate. Discussing the role of social presence in the learning experience is particularly important, as is examining overlaps and departures between the theory that grounds the CoI framework and the theories that ground disciplinary pedagogies. If researchers determine that the CoI framework is appropriate for their disciplinary context, then we recommend modifying the CoI survey to include specific questions about the social learning that their discipline values.

We additionally advocate for more research that examines the interpretation of particular survey items and categories. We are particularly interested in whether the four aspects of social presence that resulted from our factor analysis are relevant to other contexts.

\section{Acknowledgements}

This project was funded by a 2018 Conference on College Composition and Communication Emergent Researcher Award. We are also grateful to Dr. Mary Gallagher (Kent State University at Stark) for her assistance with the statistical analysis of the survey data. 


\section{References}

Akyol, Z., \& Garrison, D. R. (2008). The development of a community of inquiry over time in an online course: Understanding the progression and integration of social, cognitive, and teaching presence. Journal of Asynchronous Learning Networks, 12(3), 3-22.

Annand, D. (2011). Social presence within the community of inquiry framework. The International Review of Research in Open and Distance Learning, 12(5), 40-56.

Arbaugh, J. B., Cleveland-Innes, M., Diaz, S. R., Garrison, D. R., Ice, P., Richardson, J. C., \& Swan, K. P. (2008). Developing a community of inquiry instrument: Testing a measure of the Community of Inquiry framework using a multi-institutional sample. The Internet and Higher Education, 11, 133-136. doi:10.1016/j.iheduc.2008.06.003

Arbaugh, J. B., Bangert, A., \& Cleveland-Innes, M. (2010). Subject matter effects and the community of inquiry (CoI) framework: An exploratory study. Internet and Higher Education, 13, 37-44.

Armellini, A., \& De Stefani, M. (2016). Social presence in the 21st century: An adjustment to the Community of Inquiry framework. British Journal of Educational Technology, 47(6), 12021216. doi:10.1111/bjet.12302

Bartlett, M. S. (1954). A note on the multiplying factors for various $\chi 2$ approximations. Journal of the Royal Statistical Society: Series B (Methodological), 16(2), 296-298. doi:

10.1111/j.2517-6161.1954.tb00174.x

Boston, W., Díaz, S. R., Gibson, A. M., Ice, P., Richardson, J., \& Swan, K. (2009). An exploration of the relationship between indicators of the community of inquiry framework and retention in online programs. Journal of Asynchronous Learning Networks, 13(3), 67-83.

Bruffee, K. A. (1999). Collaborative learning: Higher education, interdependence, and the authority of knowledge. Johns Hopkins University Press.

Caskurlu, S. (2018). Confirming the subdimensions of teaching, social, and cognitive presences: A construct validity study. Internet and Higher Education, 39, 1-12.

https://doi.org/10.1016/j.iheduc.2018.05.002

Carlon, S., Bennett-Woods, D., Berg, B., Claywell, L., LeDuc, K., Marcisz, N., Mulhall, M., Noteboom, T., Snedden, T., Whalen, K., \& Zenoni, L. (2012). The community of inquiry instrument: Validation and results in online health care disciplines. Computers \& Education, 59(2), 215-221.

Cattell, R. B. (1966). The scree test for the number of factors. Multivariate Behavioral Research, 1(2), 245-276.

Cleveland-Innes, M., \& Campbell, P. (2012). Emotional presence, learning, and the online learning environment. The International Review of Research in Open and Distributed Learning, 13(4), 269-292. 
Corbett, S. J., LaFrance, M., \& Decker, T. (2014). Peer pressure, peer power: Theory and practice in peer review and response for the writing classroom. Fountainhead Press.

Dewey, J. (1993). How We Think. Health.

Díaz, S., R., Swan, K., Ice, P., \& Kupczynski, L. (2010). Student ratings of the importance of survey items, multiplicative factor analysis, and the validity of the community of inquiry survey. Internet and Higher Education, 13, 22-30. doi:10.1016/j.iheduc.2009.11.004

Garrison, R. D. (2017). E-learning in the 21st century: A Community of Inquiry framework for research and practice (3rd ed.). Routledge.

Garrison, D. R. (2007). Online community of inquiry review: Social, cognitive, and teaching presence issues. Online Learning 11(1), 61-72.

Garrison, D. R., \& Arbaugh, J. B. (2007). Researching the community of inquiry framework: Review, issues, and future directions. Internet and Higher Education, 10(3), 157-172.

Garrison, R. D., Anderson, T., \& Archer, W. (2000). Critical inquiry in a text-based environment: Computer conferencing in higher education. The Internet and Higher Education, 2(2-3), 87105.

Gere, A. R. (1987). Writing groups: History, theory, and implications. Southern Illinois University Press.

Gillam, K. W., \& Shannon, R. (2013). Re-embodying online composition: Ecologies of writing in unreal time and space. Computers and Composition 30, 24-36. https://doi.org/10.1016/j.compcom.2012.11.001

Hilliard, L. P., \& Stewart, M. K. (2019). Time well spent: Creating a community of inquiry in blended first-year writing courses. The Internet and Higher Education, 41, 11-24. https://doi.org/10.1016/j.iheduc.2018.11.002

Kaiser, H. F. (1970). A second generation little jiffy. Psychometrika, 35(4), 401-415.

Kaiser, H. F. (1974). An index of factorial simplicity. Psychometrika, 39(1), 31-36.

Kennedy, K., \& Howard, R. M. (2014). Collaborative writing, print to digital. In G. Tate, A. R. Taggart, K. Schick, \& H. B. Hessler, A Guide to Composition Pedagogies, Oxford University Press (pp. 37-54).

Kozan, K., \& Richardson, J. C. (2014). New exploratory and confirmatory factor analysis insights into the community of inquiry survey. The Internet and Higher Education, 23, 39-47.

Kreijns, K., Van Acker, F., Vermeulen, M., \& Van Buuren, H. (2014). Community of Inquiry: Social presence revisited. E-learning and Digital Media, 11(1), 5-18. 
Lambert J. L., \& Fisher, J. L. (2013). Community of inquiry framework: Establishing community in an online course. Journal of Interactive Online Learning, 12(1), 1-16.

Lowenthal, P. R., \& Snelson, C. (2017). In search of a better understanding of social presence: An investigation into how researchers define social presence. Distance Education, 38(2), 141159.

Peacock, S., \& Cowan, J. (2019). Promoting a sense of belonging in online learning communities of inquiry. Online Learning Journal, 23(2), 67-81.

Rockinson-Szapkiw, A. J., Wendt, J., Wighting, M., \& Nisbet, D. (2016). The predictive relationship among the Community of Inquiry Framework, perceived learning and online, and graduate students' course grades in online synchronous and asynchronous courses. International Review of Research in Open and Distributed Learning, 17(3), 18-34.

Shea, P., \& Bidjerano, T. (2009). Community of Inquiry as a theoretical framework to foster "epistemic engagement" and "cognitive presence" in online education. Computers \& Education, 52(3), 543. https://10.1016/j.compedu.2008.10.007

Shea, P., Hayes, S., Smith, S. U., Vickers, J., Bidjerano, T., Pickett, A., ... \& Jian, S. (2012). Learning presence: Additional research on a new conceptual element within the Community of Inquiry (CoI) framework. The Internet and Higher Education, 15(2), 89-95.

Short, J., Williams, E., \& Christie, B. (1976). The social psychology of telecommunications. John Wiley \& Sons.

Stenbom, S. (2018). A systematic review of the community of inquiry survey. The Internet and Higher Education, 39, 22-32. https://10.1016/j.iheduc.2018.06.001

Stewart, M. K. (2019). The community of inquiry survey: An assessment instrument for online writing courses. Computers \& Composition, 52, 37-52. https://doi.org/10.1016/j.compcom.2019.01.001

Stewart, M. K., Cunningham, J. M., Stillman-Webb, N., \& Hilliard, L. (in press). How and what students learn in hybrid and online FYC: A multi-institutional survey study of student perceptions. College Composition and Communication.

Wardle, E., \& Adler-Kassner, L. (2015). Naming what we know: Threshold concepts of writing studies. Utah State University Press.

Wicks, D. A., Craft, B. B., Mason, G. N., Gritter, K., \& Bolding, K. (2015). An investigation into the community of inquiry of blended classrooms by a faculty learning community. The Internet and Higher Education, 25, 53-62. 


\section{Appendix A Modifications to CoI Survey}

\begin{tabular}{|c|c|}
\hline Original CoI Survey & Modifications for Writing Studies \\
\hline \multicolumn{2}{|c|}{ Teaching Presence } \\
\hline $\begin{array}{l}\text { 1. The instructor clearly communicated important } \\
\text { course topics. }\end{array}$ & No change. \\
\hline $\begin{array}{l}\text { 2. The instructor clearly communicated important } \\
\text { course goals. }\end{array}$ & No change. \\
\hline $\begin{array}{l}\text { 3. The instructor provided clear instructions on how } \\
\text { to participate in course learning activities. }\end{array}$ & No change. \\
\hline $\begin{array}{l}\text { 4. The instructor clearly communicated important } \\
\text { due dates/time frames for learning activities. }\end{array}$ & No change. \\
\hline $\begin{array}{l}\text { 5. The instructor was helpful in identifying areas of } \\
\text { agreement and disagreement on course topics that } \\
\text { helped me to learn. }\end{array}$ & No change. \\
\hline $\begin{array}{l}\text { 6. The instructor was helpful in guiding the class } \\
\text { towards understanding writing strategies in a way } \\
\text { that improved my writing process. }\end{array}$ & $\begin{array}{l}\text { Original phrasing: "The instructor was helpful in } \\
\text { guiding the class towards understanding course } \\
\text { topics in a way that helped me clarify my } \\
\text { thinking." }\end{array}$ \\
\hline $\begin{array}{l}\text { 7. The instructor helped to keep course participants } \\
\text { engaged and participating in productive dialogue. }\end{array}$ & No change. \\
\hline $\begin{array}{l}\text { 8. The instructor helped keep the course participants } \\
\text { on task in a way that helped me to learn. }\end{array}$ & No change. \\
\hline $\begin{array}{l}\text { 9. The instructor encouraged course participants to } \\
\text { explore new concepts in this course. }\end{array}$ & No change. \\
\hline $\begin{array}{l}\text { 10. Instructor actions reinforced the development of } \\
\text { a sense of community among course participants. }\end{array}$ & No change. \\
\hline $\begin{array}{l}\text { 11. The instructor helped to focus discussion on } \\
\text { relevant issues in a way that helped me to learn. }\end{array}$ & No change. \\
\hline $\begin{array}{l}\text { 12. The instructor provided feedback that helped me } \\
\text { understand my strengths and weaknesses as a writer. }\end{array}$ & $\begin{array}{l}\text { Original phrasing: "The instructor provided } \\
\text { feedback that helped me understand my strengths } \\
\text { and weaknesses." }\end{array}$ \\
\hline $\begin{array}{l}\text { 13. The instructor provided feedback in a timely } \\
\text { fashion. }\end{array}$ & No change. \\
\hline
\end{tabular}

\section{Social Presence}

\begin{tabular}{l|l}
\hline $\begin{array}{l}\text { 14. Getting to know other course participants gave } \\
\text { me a sense of belonging in the course. }\end{array}$ & No change. \\
\hline $\begin{array}{l}\text { 15. I was able to form distinct impressions of some } \\
\text { course participants. }\end{array}$ & No change. \\
\hline $\begin{array}{l}\text { 16. Online or web-based communication is an } \\
\text { excellent medium for social interaction. }\end{array}$ & No change. \\
\hline $\begin{array}{l}\text { 17. I felt comfortable conversing through the online } \\
\text { medium. }\end{array}$ & No change. \\
\hline $\begin{array}{l}\text { 18. I felt comfortable participating in the course } \\
\text { discussions. }\end{array}$ & No change. \\
\hline
\end{tabular}




\begin{tabular}{l|l}
\hline $\begin{array}{l}\text { 19. I felt comfortable interacting with other course } \\
\text { participants. }\end{array}$ & No change. \\
\hline $\begin{array}{l}\text { 20. I felt comfortable disagreeing with other course } \\
\text { participants while still maintaining a sense of trust. }\end{array}$ & No change. \\
\hline $\begin{array}{l}\text { 21. I felt that my point of view was acknowledged } \\
\text { by other course participants. }\end{array}$ & No change. \\
\hline $\begin{array}{l}\text { 22. Online discussions helped me to develop as a } \\
\text { writer. }\end{array}$ & $\begin{array}{l}\text { Original phrasing: "Online discussions help me to } \\
\text { develop a sense of collaboration." }\end{array}$ \\
\hline & $\begin{array}{l}\text { Added: Interacting with classmates improved my } \\
\text { writing. }\end{array}$ \\
\hline
\end{tabular}

Cognitive Presence

\begin{tabular}{|c|c|}
\hline $\begin{array}{l}\text { 23. Course assignments increased my interest in } \\
\text { writing-related issues. }\end{array}$ & $\begin{array}{l}\text { Original phrasing: "Problems posed increased } \\
\text { my interest in course issues." }\end{array}$ \\
\hline 24. Course activities piqued my curiosity. & No change. \\
\hline $\begin{array}{l}\text { 25. I felt motivated to explore questions raised in } \\
\text { this course." }\end{array}$ & $\begin{array}{l}\text { Original phrasing: "I felt motivated to explore } \\
\text { content related questions." }\end{array}$ \\
\hline $\begin{array}{l}\text { 26. I utilized a variety of information sources to } \\
\text { learn more about the topics I wrote about. }\end{array}$ & $\begin{array}{l}\text { Original phrasing: "I utilized a variety of } \\
\text { information sources to explore problems posed in } \\
\text { this course." }\end{array}$ \\
\hline $\begin{array}{l}\text { 27. Brainstorming and finding relevant information } \\
\text { improved my writing process. }\end{array}$ & $\begin{array}{l}\text { Original phrasing: "Brainstorming and finding } \\
\text { relevant information helped me resolve content } \\
\text { related questions." }\end{array}$ \\
\hline $\begin{array}{l}\text { 28. Online discussions were valuable in helping } \\
\text { me appreciate different perspectives. }\end{array}$ & No change. \\
\hline $\begin{array}{l}\text { 29. Combining new information helped me answer } \\
\text { questions raised in course activities. }\end{array}$ & No change. \\
\hline $\begin{array}{l}\text { 30. Learning activities helped me construct } \\
\text { explanations/solutions. }\end{array}$ & No change. \\
\hline $\begin{array}{l}\text { 31. Reflecting on course activities and discussions } \\
\text { helped me understand fundamental concepts about } \\
\text { writing. }\end{array}$ & $\begin{array}{l}\text { Original phrasing: "Reflection on course } \\
\text { content and discussions helped me } \\
\text { understand fundamental concepts in this } \\
\text { class." }\end{array}$ \\
\hline $\begin{array}{l}\text { 32. I can describe ways to test and apply the writing } \\
\text { skills I learned in this course. }\end{array}$ & $\begin{array}{l}\text { Original phrasing: "I can describe ways to test } \\
\text { and apply the knowledge created in this course." }\end{array}$ \\
\hline $\begin{array}{l}\text { 33. I have developed solutions to issues raised in } \\
\text { this course that can be applied in practice. }\end{array}$ & $\begin{array}{l}\text { Original phrasing: "I have developed solutions to } \\
\text { course problems that can be applied in practice." }\end{array}$ \\
\hline $\begin{array}{l}\text { 34. I can apply the writing skills I learned in this } \\
\text { course to my work or other non-class related } \\
\text { activities. }\end{array}$ & $\begin{array}{l}\text { Original phrasing: "I can apply the knowledge } \\
\text { created in this course to my work or other non- } \\
\text { class related activities." }\end{array}$ \\
\hline
\end{tabular}




\section{Appendix B \\ CoI Survey in Writing Studies Survey}

\section{Social Presence}

\section{Social Presence}

1. I was able to form distinct impressions of some course participants.

\section{Social Comfort}

2. I felt comfortable conversing through the online medium.

3. I felt comfortable participating in the course discussions.

4. I felt comfortable interacting with other course participants.

5. I felt comfortable disagreeing with other course participants while still maintaining a sense of trust.

6. I felt that my point of view was acknowledged by other course participants.

\section{Social Learning}

7. Online discussions helped me to develop as a writer.*

8. Interacting with classmates improved my writing.*

9. Getting to know other course participants gave me a sense of belonging in the course.

\section{Attitude}

10. Online or web-based communication is an excellent medium for social interaction.

[open ended] What types of interactions with other people facilitated your learning in the course?**

\section{Cognitive Presence}

Triggering Event

11. Course assignments increased my interest in writing-related issues.*

12. Course activities piqued my curiosity.

13. I felt motivated to explore questions raised in this course.

\section{Exploration}

14. I utilized a variety of information sources to learn more about the topics I wrote about.*

15. Brainstorming and finding relevant information improved my writing process.*

16. Online discussions were valuable in helping me appreciate different perspectives.

\section{Integration}

17. Combining new information helped me answer questions raised in course activities.

18. Learning activities helped me construct explanations/solutions.

19. Reflecting on course activities and discussions helped me understand fundamental concepts about writing.* 


\section{Resolution}

20. I can describe ways to test and apply the writing skills I learned in this course.*

21. I have developed solutions to issues raised in this course that can be applied in practice.

22. I can apply the writing skills I learned in this course to my work or other non-class related activities.*

[open ended] What was the most useful thing that you learned about, or learned how to do, in your composition class?**

[open ended] Which course activities specifically facilitated your learning?**

\section{Teaching Presence}

\section{Design \& Organization}

23. The instructor clearly communicated important course topics.

24. The instructor clearly communicated important course goals.

25. The instructor provided clear instructions on how to participate in course learning activities.

26. The instructor clearly communicated important due dates/time frames for learning activities.

\section{Facilitating Discourse}

27. The instructor was helpful in identifying areas of agreement and disagreement on course topics that helped me to learn.

28. The instructor was helpful in guiding the class towards understanding writing strategies in a way that improved my writing process.*

29. The instructor helped to keep course participants engaged and participating in productive dialogue.

30. The instructor helped keep the course participants on task in a way that helped me to learn.

31. The instructor encouraged course participants to explore new concepts in this course.

32. Instructor actions reinforced the development of a sense of community among course participants.

\section{Direct Instruction}

33. The instructor helped to focus discussion on relevant issues in a way that helped me to learn.

34. The instructor provided feedback that helped me understand my strengths and weaknesses as a writer.*

35. The instructor provided feedback in a timely fashion.

[open ended] Explain the most important thing that your instructor did to support your success in the course.**

*Discipline-specific item. We recommend researchers in other disciplines modify these items to make them specific to the social learning they expect their students to achieve/experience.

**The qualitative results from the open-ended questions are reported elsewhere (Stewart et al., in press). 